\title{
An uphill battle - getting rehab into mainstream rural medicine
}

Rehabilitation healthcare professionals starting out in a rural hospital need to socialise with and educate clinicians, develop community networks and support groups and build referral systems, if they want to be effective and get to grips with a resource-scarce environment.

That's the advice Maryke Bezuidenhout, a physiotherapist of 14 years' experience at Manguzi Hospital in far northern KwaZuluNatal and chairperson of the Rural Rehab South Africa (RuReSa), had for colleagues at the Rural Doctors Association of South Africa (RuDASA) annual conference in Grahamstown this August.

Bezuidenhout believes that a crucial adjunct to clinical knowledge is the ability to socialise and befriend your medical colleagues. 'You can draw up a formal system and it might work in the private sector, but with the staff turnover in public, you ride on personality and connecting. People are less likely to be shitty to you if they know you personally.' She and her rehab colleagues at Manguzi use a WhatsApp group. Instead of making it 'super-clinical, we have regular chats with our doctors. When we talk about stroke, we talk about the lived experience of stroke survivors', she explains. Bezuidenhout said it was a mistake to assume doctors were up to date with rehabilitation medicine. She gave the example of how crucial bowel and bladder control was to spinal patients and how quickly patients could develop chronic kidney disease. 'Unattended, a patient can die a long, slow death - you have to tailor a programme suited to the specific individual and get all the consumables to them at home - it takes a lot of co-ordination. She also urged doctors to 'look for all things an able-bodied person would have', citing patients with mental disorders who research had shown died 15 - 20 years earlier than the general population. 'It's not the mental health: it's that doctors don't treat them as a normal person with normal problems. The response is usually "go and see the psychiatrist".

\section{Networking across rutted rural roads}

Speaking in the midst of an obstacle course set up to give RuDASA delegates a mild feel of what it might be like to negotiate a rocky river bed or mountainside path in a wheelchair, she stressed the utility of midlevel and community healthcare workers. With so few rehabilitation professionals available, nurturing both of these cadres and holding education and training workshops so that they could assess and follow up patients in their homes was 'vital' to successful outcomes. Linking community healthcare workers to any disabled peoples' organisations (or creating them) further strengthened rehabilitative care.

Bezuidenhout urged newly posted rehab workers to begin their own electronic monitoring system for rehabilitative devices, which very often went missing when patients no longer needed them or died. Also, if there was no rehab referral system at the hospital, 'don't reinvent the wheel - find out from a functioning hospital - and don't wait for people to refer to you. A functioning referral system takes years to build. Giving doctors pamphlets won't work, but quarterly talks to your nurses and doctors, and sharing outcomes do. Go and pick patients out of the outpatients' queue, screen the benches,' she urged.

\section{Chris Bateman}

chrisb@hmpg.co.za

S Afr Med J 2016;106(10):960.

DOI:10.7196/SAMJ.2016.v106i10.11437 